\title{
Claspin as a biomarker of human papillomavirus- related high grade lesions of uterine cervix
}

\author{
Maria Benevolo ${ }^{1 *}$, Antonio Musio ${ }^{2,3}$, Amina Vocaturo ${ }^{1}$, Maria Gabriella Donà ${ }^{4}$, Francesca Rollo ${ }^{1}$, Irene Terrenato ${ }^{5}$, \\ Mariantonia Carosi', Edoardo Pescarmona ${ }^{1}$, Giuseppe Vocaturo ${ }^{6}$ and Marcella Mottolese ${ }^{1}$
}

\begin{abstract}
Background: Claspin is a nuclear protein involved in DNA replication and damage response and is a key mediator for the S-phase checkpoint. Claspin expression is significantly high in several human solid tumors. Furthermore, high levels of claspin have been found in cervical cancer cell lines. Nevertheless, no data are available regarding claspin expression in cervical tissues.

Methods: In order to investigate whether claspin immunoreactivity is related to the lesion severity and High-Risk (HR) HPV infection, we analyzed claspin expression by immunohistochemistry in a series of cervical biopsies which represent the steps occurring during cervical carcinogenesis (normal tissues, Cervical Intraepithelial Neoplasias 1, 2 and 3, Squamous Cell Carcinomas). All patients also had a cervico-vaginal sample for HPV testing, collected immediately before the colposcopy-guided biopsy. The HR-HPV DNA detection was performed by the HR-HPV Hybrid Capture 2 test. HPV genotyping was performed using the Linear Array HPV Genotyping Test.

Results: Our results evidenced a constant and significant increase of the rate of claspin positivity from the normal tissues to carcinomas ( $p x^{2}$ trend $<0.0001$ ). In fact, the normal tissues displayed either no or faint claspin immunoreactivity, whereas a moderate/high positivity was observed in 16\% of the CIN1, $76 \%$ of the CIN2, $87.5 \%$ of the CIN3 and 93.3\% of the cancers. Moreover, we found a statistically significant correlation between claspin expression and HR-HPV infection ( $\left.p x^{2}<0.0001\right)$, irrespective of the genotype. Finally, we demonstrated the feasibility of claspin immunostaining in cervical cytology.

Conclusions: Our findings indicate that in vivo claspin expression is significantly related to HR-HPV infection and lesion grade both in histological and cytological samples. Therefore, the analysis of claspin expression could be clinically relevant in the diagnosis of HPV-related cervical lesions, in particular when applied to cervico-vaginal cytology. Moreover, giving information on the proliferation rate of each lesion, claspin immunostaining may contribute to the evaluation of progression risk, thus being helpful in patient management. Nevertheless, only large prospective studies may clarify the true clinical usefulness of claspin expression in distinguishing lesions with different progression potential.
\end{abstract}

Keywords: Claspin, Human papillomavirus, Uterine cervix, Biomarker

\section{Background}

Claspin is a nuclear protein involved in both DNA replication and damage response and is a key mediator for the S-phase checkpoint. Its main function is to facilitate phosphorylation of the effector kinase Chk1 by the sensor kinase ATR in response to replication stresses [1-3]. Inhibition of claspin, as well as ATR and Chk1, greatly

\footnotetext{
* Correspondence: benevolo@ifo.it

${ }^{1}$ Pathology Department, Regina Elena Cancer Institute, Via Elio Chianesi 53, 00144, Rome, Italy

Full list of author information is available at the end of the article
}

reduces cell survival, likely inducing alterations in cell cycle checkpoints and DNA repair systems [4]. These alterations may lead to genomic instability triggering cancer development [5,6]. However, the expression of claspin significantly increases in several human solid tumors such as in colon, lung, bladder and breast cancer [7]. Despite these findings, to date no data are available concerning claspin expression in human cervical carcinogenesis which represents a paradigmatic model of cancer development. Cervical cancer, in fact, arises via a series of well-defined intermediate lesions throughout

\section{Biomed Central}


various steps of cellular atypia and its cause, i.e. the High Risk Human Papillomavirus (HR-HPV) infection, is well established. The oncogenic potential of HR-HPV lies in the two major viral oncoproteins, E6 and E7, which bind to and modulate a number of different cellular proteins, interfering with almost all the cellular processes and inducing genomic instability and cell proliferation. Interestingly, recent in vitro data showed high claspin baseline level in cervical cancer cell lines. In addition, the cell lines expressing the HPV-E7 oncoprotein also showed an increased claspin turnover [8].

Therefore, in addition to viral markers, such as E6/E7 mRNA or protein detection [9,10], cellular molecules related to cell cycle control, may be worth of investigation in cervical pathology. Several host proteins, such as p16 and Ki67 [11-13], have been studied, possibly representing novel biomarkers which are strictly linked to the host changes induced by HPV. Yet, none of them has been introduced in clinical guide lines so far, although p16 expression is currently used by many pathologists.

In the present study, we addressed the question of whether the expression of claspin is associated to human uterine cervix transformation in vivo and, as a consequence, if it could be used as a putative biomarker of dysplasia and/or HR-HPV infection. To this end, we firstly analyzed claspin expression by western blotting in a series of both HPV negative and positive non tumorigenic and tumorigenic cell lines. Furthermore, we determined immunohistochemical claspin distribution, in parallel with HR-HPV DNA status, in a retrospective series of human cervical biopsies which encompass a representative spectrum of dysplastic and neoplastic cervical lesions, aiming at investigating whether claspin expression correlated with the grade of the lesions and HR-HPV infection in vivo.

Finally, in the knowledge that identifying molecular alterations in cytological specimens might improve the detection of cervical lesions at higher risk of transformation in both primary screening and triage settings, we evaluated claspin distribution in a subset of available cytological samples, including negative, low and high grade squamous intraepithelial lesions, collected in parallel with the cervical biopsies.

\section{Materials and methods \\ Cell lines}

The human cell lines NHEK, HK-168, SiHa, CaSki, and HeLa were used. They were kindly provided by Dr. Federico De Marco (Regina Elena Cancer Institute, Rome, Italy). NHEK is a HPV negative human keratinocyte diploid cell line; HK-168 is a non tumorigenic cell line derived from primary human keratinocytes transfected with HPV16 and containing about 1-2 viral copies/aploid genome [14]. $\mathrm{SiHa}, \mathrm{CaSki}$ and HeLa are cervical carcinoma-derived cell lines (the SiHa and CaSki from squamous cancer and the HeLa from an adenocarcinoma) containing HPV sequences (SiHa: 1 HPV16 genome copy per cell; CaSki: 500-600 HPV16 genome copies per cell; HeLa: 10-50 HPV18 genome copies per cell).

NHEK and HK-168 were cultured in a K-SMC (Gibco, Invitrogen, Milan, Italy) definite medium while $\mathrm{SiHa}$, CaSki and HeLa were cultured in DMEM supplemented with $10 \%$ of fetal bovine serum and antibiotics (penicillin $100 \mathrm{U} / \mathrm{mL}$, and streptomycin $100 \mu \mathrm{g} / \mathrm{mL}$ ).

\section{Western blotting}

Analysis with rabbit polyclonal antibody against claspin (Bethyl Laboratories, Montgomery, TX, USA) was performed according to a published protocol [5]. Briefly, the samples were boiled in sample buffer and separated by SDS-PAGE. The proteins were, then, transferred to a nitrocellulose membrane (Amersham Pharmacia Biotech, Freiburg, Germany) and incubated with the primary antibody. After removing the unbound primary antibody, the membranes were incubated with a secondary antibody-peroxidase conjugate (Sigma Chemical Co., MO, USA), processed for detection by chemiluminescence (Amersham), and imaged on Biomax film (Kodak, Milan, Italy). A rabbit polyclonal antibody against Actin (Santa Cruz Biotechnology, CA, USA) was used as a loading control.

\section{Histological samples}

This study was reviewed by the Ethics Committee of the Regina Elena Cancer Institute. We selected 80 cases from the Regina Elena Cancer Institute files, which had been collected between June 2006 and July 2009, submitted to a colposcopy-guided cervical biopsy immediately after a cervico-vaginal sampling for HPV testing. All histological slides were independently reviewed by two experienced pathologists and an adjudicated final diagnosis was established. Of the 80 formalin fixed biopsies, 9 had no relevant lesions (herein referred to as WNL: within normal limits), 19 were diagnosed as Cervical Intraepithelial Neoplasia (CIN) 1, 21 as CIN2, 16 as CIN3 and 15 as invasive Squamous Cell Carcinomas (SCC). For the purpose of our study, the WNL and CIN1 diagnoses were referred to as CIN2-, while CIN2, CIN3 and SCC were referred to as CIN2+. Therefore, on the basis of this classification, we analyzed $28 \mathrm{CIN} 2$ - and $52 \mathrm{CIN} 2+$ cases. This sample size was adequate to detect a significant difference at $1 \%$ level with a statistical power of $90 \%$, according to an a priori power calculation based on data from our laboratory regarding Ki67 reactivity in cervical pathology (data not shown). In fact, given that Ki67 is a well known proliferation marker which is widely applied in solid tumors [15], we expected a similar distribution of immunoreactivity for 
claspin. The sample size calculation identified a minimum number of 54 patients, 27 per CIN2- group and 27 per CIN2+ group.

\section{Cytological samples}

Of the 80 cervico-vaginal specimens collected in PreservCyt (Hologic, Rome, Italy) for HPV testing, 19 had a residual sample which was sufficient to obtain thin layer slides which were adequate for both morphological and immunocytochemical analyses. The thin layer slides were prepared using the ThinPrep 2000 System (Hologic), following the manufacturer's instructions. Papanicolau slides were interpreted independently from all other findings, and classified according to the Bethesda 2001 guidelines [16], by two experienced cytopathologists. An adjudicated final report was established and reported as 3 Negative for Intraepithelial Lesion or Malignancy (NILM), 7 Low-Grade Intraepithelial Lesions (L-SIL) and 9 High-Grade Intraepithelial Lesions (H-SIL).

\section{Claspin immunostaining}

The immunohistochemistry (IHC) performed to detect claspin expression was carried out on $3 \mu \mathrm{m}$ thick sections cut from formalin-fixed paraffin embedded blocks. We used a monoclonal antibody which was kindly provided by Professor T. Halazonetis (University of Geneva Switzerland), and directed against the amino-acidic residues $785-1056$ of the full-length protein as previously described [7]. Antigen retrieval was carried out pretreating dewaxed and rehydrated slides in a water bath at $96{ }^{\circ} \mathrm{C}$ for 40 minutes in ethylenediamine tetracetic acid buffer (EDTA, pH 8.0). Immunoreactivity was revealed by means of a super sensitive streptavidinbiotin immunoperoxidase system (Novocastra, Menarini, Florence, Italy), using 3-amino-9-ethyl-carbazole as a chromogenic substrate. Nuclear staining, independent of intensity, was considered positive, excluding the basal layer in which proliferating cells are physiologically present. For each sample, we counted the positive nuclei in four to six selected High Power field (HPF, 400X magnification) representative of the lesion using an image analyzer (Eureka Interface, Menarini). A maximum of 200 immunoreactive nuclei/HPF were counted. For each sample, we calculated the mean number of the positive nuclei counted in all selected fields, thus obtaining a single value reported as nuclei/ HPF value. For the purpose of the study, on the basis of the nuclei/HPF value, we distinguished 4 different categories of claspin reactivity: negative ( 0 or less than 1 immunoreactive nuclei/HPF), low-positive ( 1 to $<20$ immunoreactive nuclei/HPF), moderate-positive (20 to 80 immunoreactive nuclei/HPF), high-positive (more than 80 immunoreactive nuclei/HPF).
The immunocytochemical analysis of the 19 available cervico-vaginal samples was performed following the above described procedure, after fixing Thin-Prep slides in $10 \%$ buffered formalin for 20 minutes followed by water rinsing. Immunostaining was considered positive when at least one cell showed nuclear reactivity either among the superficial and intermediate typical cells or among the clearly atypical cells, independently of all other findings.

\section{HPV testing}

The HR-HPV DNA detection was performed on cytological samples by the HR-HPV Hybrid Capture 2 (HC2) test (Qiagen, Milan, Italy), following the manufacturer's recommendations. Before the $\mathrm{HC} 2$ test, $2 \mathrm{~mL}$ of each sample were processed using the $\mathrm{HC} 2$ Sample Conversion Kit (Qiagen). The HR-HPV HC2 assay detects the most common 13 HR-HPV types in cervical cancer: $16,18,31,33,35,39,45,51,52,56$, 58, 59 and 68. The HPV genotyping test was performed by the PCR based Linear Array HPV Genotyping kit (Roche Diagnostics, Italy), utilizing $250 \mu \mathrm{L}$ of the residual liquid sample and following the manufacturer's instructions. This assay is able to detect 37 high, intermediate and low risk HPV types $(6,11,16$, $18,26,31,33,35,39,40,42,45,51,52,53,54,55$, $56,58,59,61,62,64,66,67,68,69,70,71,72,73$, 81, 82, 83, 84, IS39 and CP6108). Only samples that were found positive to at least one of the 13 genotypes recognized by the $\mathrm{HC} 2$ test were considered to be HPV DNA positive by PCR. Moreover, because of the higher oncogenic potential displayed by HPV 16 and 18 types [13], we divided the positive results into two categories: 1) presence of HPV 16 and/or 18 sequences with or without other genotypes (16/18 positive), 2) detection of HR-HPV genotypes other than 16 and 18, as single or multiple infections (HRHPV positive).

\section{Statistical analyses}

Data were analyzed with SPSS statistical software version 17.0. (SPSS Inc., Chicago IL, USA). The associations between variables of interest were performed by the nonparametric Pearson Chi-Square test and the KruskallWallis test, when appropriate. Analyses for trend were also carried out by using the Chi-square test for trend. A p-value $<0.05$ was considered to be statistically significant. To evaluate the sensitivity and specificity for the presence of a CIN2+ lesion, the cases showing negative or low claspin expression were considered as negative whereas the cases with moderate or high claspin immunoreactivity were regarded to as positive. 


\section{Results}

\section{In vitro claspin expression}

In order to investigate the correlation between claspin expression and uterine cervix transformation, we examined the expression of claspin by western blotting both in normal human keratinocytes (NHEK) and in a series of cell lines that resembled cervical malignancy at different stages of tumorigenesis (HK-168, SiHa, CaSki, HeLa). We found no claspin expression in the normal cell line and in the HK-168 cell line which has a basal/ parabasal keratinocyte phenotype resembling the CIN2 stage [14], while its expression was evident in $\mathrm{SiHa}$, CaSki and HeLa cervical carcinoma cell lines (Figure 1).

\section{Claspin expression in human cervical lesions}

In order to investigate whether results obtained on the cell lines could be reproduced in human cervical tissue samples, and whether claspin expression could be linked to the severity of the lesions, we analyzed this biomarker by IHC (Figure 2) in a series of 9 WNL biopsies, 19 CIN1, 21 CIN2, 16 CIN3, and 15 SCC. We calculated the mean and the median value of the claspin-positive nuclei/HPF values within each diagnostic category (Table 1). We found that WNL tissues and CIN1 showed a very scanty mean positivity of less than 10 nuclei/HPF with a median value of 0.0 . In contrast, we found a mean value of $46.8 \pm 38.8$ and a median of 36.5 in the CIN2 lesions, a mean value of $72.6 \pm 46.7$ and a median of 67.3 in the CIN3 lesions, and a mean value of $133.9 \pm 75.8$ and a median of 200.0 in the SCC. Therefore, the mean and median claspin-positive nuclei/HPF values consistently and significantly increased from CIN1 to SCC (p Kruskall-Wallis <0.0001). Of interest, the minimum claspin-positive nuclei/HPF value appeared to be independent of the severity of the histological diagnosis, whereas the maximum value showed a consistent increase from WNL to SCC samples.

Afterwards, according to the four-score categories of reactivity described in the Materials and Methods

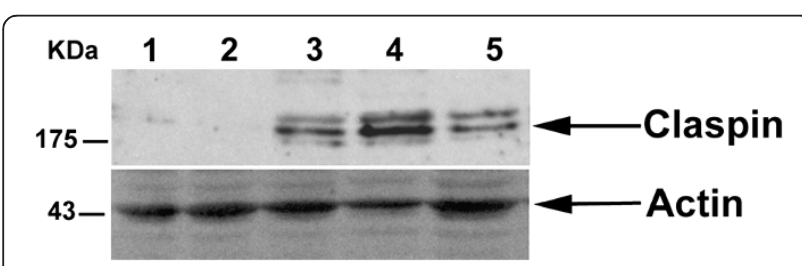

Figure 1 Western blot analysis of cell lines. Western blot analysis with a claspin specific antibody performed on NHEK (lane 1), HK-168 (lane 2), SiHa (lane 3), CaSki (lane 4), HeLa cell lines (lane 5). Actin was used as an internal control for sample loading. Because claspin activity is regulated by phosphorylation, the high molecular weight band might correspond to a phosphorylated form while the low molecular weight band might be due to protein degradation. section, we compared the proportion of the negative/low positive and the moderate/high positive cases within each histological category (Figure 3). The 9 WNL tissues were mostly negative, only two cases showing low claspin positivity. Conversely, we observed a moderate/high positivity in 3 out of the 19 CIN1 lesions (15.8\%), in 16 out of the 21 CIN2 lesions (76.2\%), in 14 out of the 16 CIN3 lesions (87.5\%), and in 14 out of the 15 SCC (93.3\%). Therefore, starting from the WNL tissues through to carcinomas, we observed a constant and significant increase of claspin expression ( $\left.\mathrm{px}_{\text {trend }}^{2}<0.0001\right)$. In addition, claspin showed a high sensitivity for CIN2+ lesion (84.6\%), and an even higher specificity (89.3\%) (data not shown). However, due to the limited and nonrandomly selected series of cases, the accuracy indicator values should be interpreted with caution.

\section{Correlation between claspin immunoreactivity and HR-HPV infection}

In order to investigate the correlation between claspin expression and HR-HPV infection, we compared the IHC findings with the $\mathrm{HC} 2$ results (Table 2). We observed a statistically significant correlation between moderate/high claspin expression and HR-HPV infection $\left(\mathrm{p}\left(\chi^{2}\right)<0.0001\right)$. In fact, 46 out of the 47 moderate/high claspin positive cases were HR-HPV positive (97.8\%). In addition, 44 out of the 46 claspin positive/HR-HPV positive cases (95.6\%) were CIN2+, whereas among the 23 claspin negative/HR-HPV positive cases we found only 8 CIN2+ lesions (34.7\%). Therefore, among the HR-HPV positive cases, immunoreactivity for claspin seems to be associated with presence of a CIN2+ lesion.

Furthermore, we performed a genotyping test in 58 out of the $69 \mathrm{HC} 2$ positive cases. Overall, 3 cases were excluded from the analysis, because they showed positivity for one or more HPV types different from the 13 HR-HPV types officially detected by the $\mathrm{HC} 2$ test, probably due to the well documented crossreactivity of this assay with other HPV types. All the remaining 55 cases were positive for one or more of the $13 \mathrm{HC} 2 \mathrm{HR}-\mathrm{HPV}$ types. In particular, as shown in Table 3, 30 out of 55 specimens presented the HPV16 and/or 18 types (54.5\%), while 25 displayed other HR genotypes $(45.5 \%)$. Comparing the distribution of claspin immunostaining with the PCR findings, we found no significant association between claspin immunoreactivity and HPV16/18 infection. In fact, even though 22 out of the $30 \mathrm{HPV} 16 / 18$ positive cases showed moderate/high claspin immunostaining (73\%), we found a not statistically significant difference in moderate/high immunoreactivity rate in comparison with the samples infected by other HR-HPV genotypes (16 out of 25 cases, $64 \% ; \mathrm{p}=0.65$ ). 

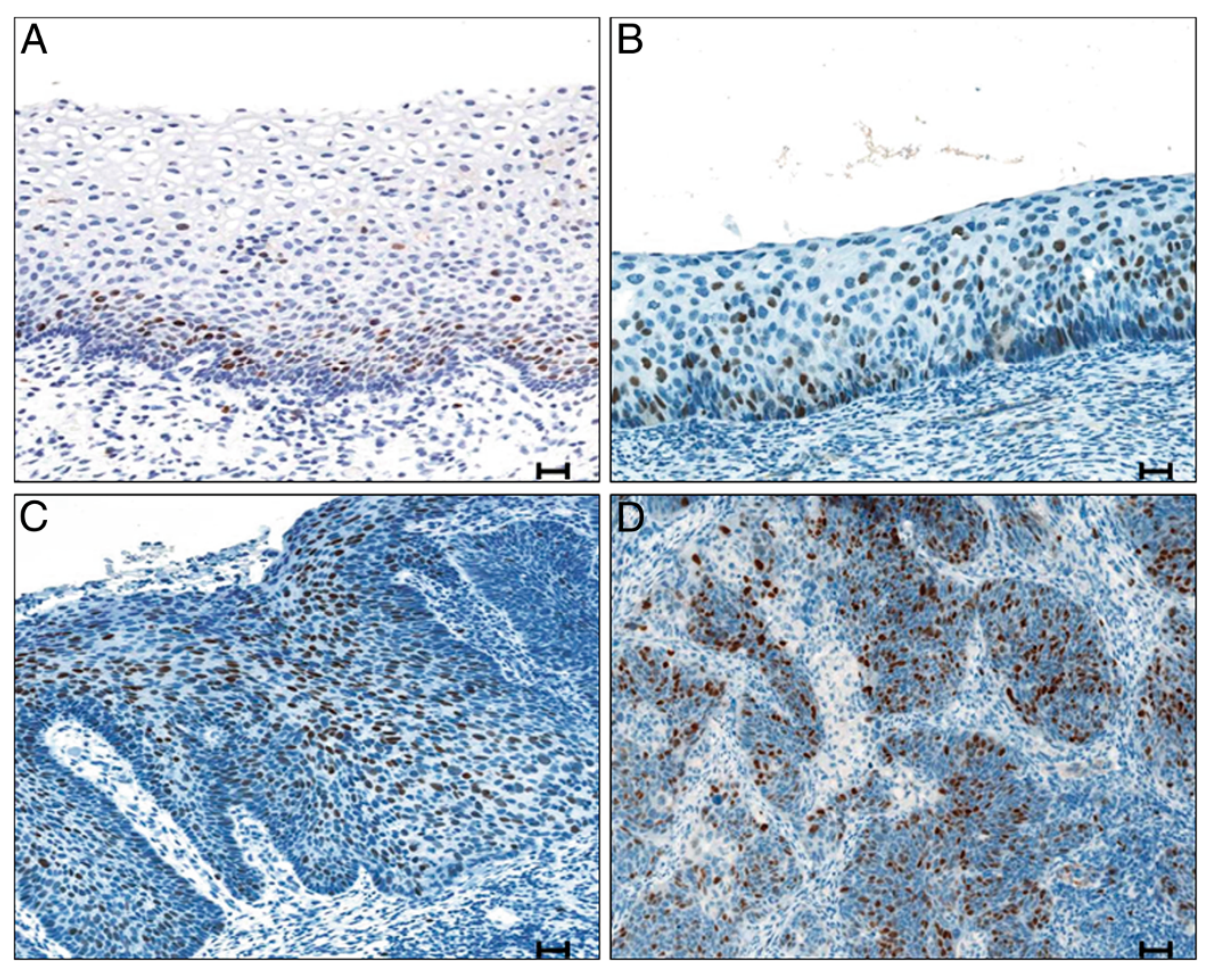

Figure 2 Immunohistochemical staining of cervical biopsies for claspin expression. A: CIN1 showing low immunoreactivity. B: CIN2 showing moderate immunoreactivity. C: CIN3 showing high immunoreactivity. D: Squamous Cell Carcinoma showing high immunoreactivity. Counterstaining with haematoxylin. Magnification 20X, scale bar $=30 \mu \mathrm{m}$. CIN Cervical Intraepithelial Neoplasia.

\section{Claspin expression in cervical cytology}

In order to verify whether claspin detection was feasible on cervical cytology, we evaluated its expression in the 19 available cervico-vaginal samples out of the 80 corresponding histological specimens tested, as specified in the Materials and Methods section. As shown in Table 4, despite the small number of specimens, claspin expression seems to correlate with the severity of the cellular abnormalities. In fact, only one NILM sample was claspin positive, while 4 out of the 7 L-SIL (57\%) and all the 9 H-SIL (100\%) showed claspin positive nuclei. Moreover, we found that all the 14 claspin immunoreactive cases were also $\mathrm{HC} 2$ positive and 13 out of these had a

Table 1 Distribution of claspin positive nuclei/HPF values by histological diagnosis

\begin{tabular}{lcc}
\hline & \multicolumn{2}{c}{ Claspin-positive nuclei/HPF } \\
\cline { 2 - 3 } Histology & Mean $( \pm$ SD) & Median (Min-Max) \\
\hline WNL $(n=9)$ & $0.4( \pm 0.8)$ & $0.0(0.0-1.8)$ \\
CIN1 $(n=19)$ & $7.4( \pm 13.8)$ & $0.0(0.0-51.5)$ \\
CIN2 $(n=21)$ & $46.8( \pm 38.8)$ & $36.5(1.0-148.6)$ \\
CIN3 $(n=16)$ & $72.6( \pm 46.7)$ & $67.3(2.0-159.1)$ \\
SCC $(n=15)$ & $133.9( \pm 75.8)$ & $200.0(11.8-200.0)$ \\
\hline
\end{tabular}

p(Kruskall-Wallis) $<0.0001$.

HPF, High Power Field; SD, standard deviation; WNL, Within Normal Limit; CIN, Cervical Intraepithelial Neoplasia; SCC, Squamous Cell Carcinoma. histologically confirmed lesion (4 L-SIL: 2 CIN1 and 2 CIN2; 9 H-SIL: 6 CIN2 and 3 CIN3; data not shown). It is worth noting that the only claspin positive NILM case was $\mathrm{HC} 2$ positive. However, due to the limited number of cytological cases analyzed we could not perform any statistical analysis to determine whether the observed differences were statistically significant.

\section{Discussion}

In this study, we analyzed claspin expression in a series of tissue samples which covered the different phases of

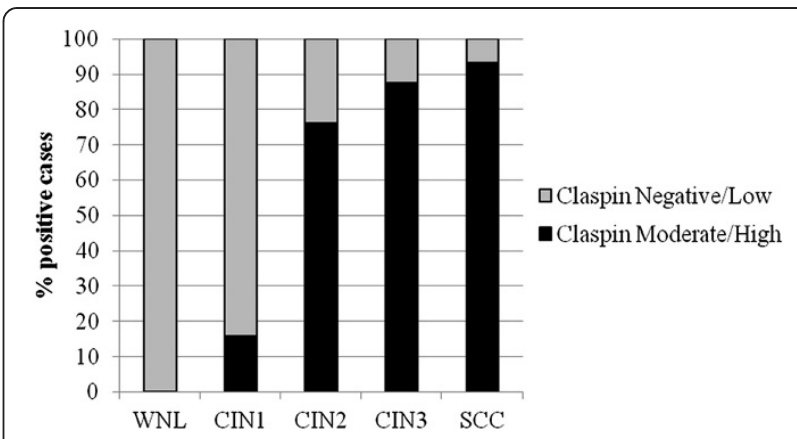

Figure 3 Claspin immunoreactivity shown by histological diagnosis. WNL Within Normal Limit.CIN Cervical Intraepithelial Neoplasia.SCC Squamous Cell Carcinoma. 
Table 2 Correlation between claspin expression and HR-HPV infection assessed by HC2 assay, stratified by histological diagnosis

\begin{tabular}{|c|c|c|c|c|c|c|}
\hline $\begin{array}{l}\text { Claspin } \\
\text { expression } \\
\text { n (\%) }\end{array}$ & HR-HPV n (\%) & $\begin{array}{l}\text { WNL } \\
n=9\end{array}$ & $\begin{array}{l}\text { CIN1 } \\
n=19\end{array}$ & $\begin{array}{c}\text { CIN2 } \\
n=21\end{array}$ & $\begin{array}{c}\text { CIN3 } \\
n=16\end{array}$ & $\begin{array}{c}\text { SCC } \\
n=15\end{array}$ \\
\hline \multirow{2}{*}{$\begin{array}{l}\text { Negative/Low } \\
33(41.2)\end{array}$} & Negative 10 (30.3) & 5 & 5 & $\backslash$ & $\backslash$ & $\backslash$ \\
\hline & Positive 23 (69.7) & 4 & 11 & 5 & 2 & 1 \\
\hline \multirow{2}{*}{$\begin{array}{l}\text { Moderate/High } \\
47 \text { (58.8) }\end{array}$} & Negative 1 (2.2) & 1 & 1 & $\backslash$ & $\backslash$ & $\backslash$ \\
\hline & Positive 46 (97.8) & 1 & 2 & 16 & 14 & 14 \\
\hline
\end{tabular}

$\mathrm{p}\left(x^{2}\right)<0.0001$.

HR-HPV, High Risk Human Papillomavirus; WNL, Within Normal Limit; CIN Cervical Intraepithelial Neoplasia; SCC, Squamous Cell Carcinoma.

uterine cervix transformation. This multistep process represents an important model of tumor development and progression. In fact, differently from the majority of human solid tumors, its causative agent, namely the HRHPV, is well defined. Nevertheless, although the steps preceding cervical cancer have been extensively studied and are known to be linked to the active transcription of the E6 and E7 viral oncogenes, only a few biomarkers of active infection have been identified to date. Claspin is a critical regulator of the ATR/Chk1 signalling axis in the G2 DNA damage checkpoint [8] and it might represent a novel marker of uterine cervix transformation. In fact, it has been demonstrated that the viral oncoproteins activate the proliferation pathway even in presence of DNA damage, concomitantly affecting a number of cellular proteins, including claspin. Therefore, claspin upregulation may represent a suitable marker of altered cellular proliferation due to HR-HPV infection. In cervical pathology, other putative biomarkers linked to proliferation control, have been investigated, e.g., Ki67, PCNA, minichromosome maintenance protein (MCM), and cyclins A and E [12,13,17]. These proteins, which are normally active during S-phase entry, are upregulated during HPV infection. Nevertheless, none of these biomarkers has been validated in a clinical setting so far. The cyclin-dependent kinase inhibitor $\mathrm{p} 16^{\mathrm{INK} 4 \mathrm{a}}$, involved in cell cycle control, has also been found overexpressed in pre-neoplastic and neoplastic lesions of the

Table 3 Association between claspin expression and HPV genotyping in 55 HC2-positive samples

\begin{tabular}{lccc}
\hline HPV genotyping & \multicolumn{3}{c}{ Claspin expression } \\
\cline { 2 - 4 } & Negative/Low & Moderate/High & Total \\
\hline HPV 16/18 positive & $8(27 \%)$ & $22(73 \%)$ & $\mathbf{3 0 ~ ( 1 0 0 \% )}$ \\
HR-HPV positive $^{\dagger}$ & $9(36 \%)$ & $16(64 \%)$ & $\mathbf{2 5 ( \mathbf { 1 0 0 } \% )}$ \\
Total & $17(31 \%)$ & $38(69 \%)$ & $55(100 \%)$
\end{tabular}

* Presence of HPV16 and/or 18 with or without other HPV types.

${ }^{\dagger}$ Presence of one or more HR-HPV types other than HPV16 and 18, among the $\mathrm{HR}$ types included in the $\mathrm{HC2}$ test.

$\mathrm{p}\left(x^{2}\right)=0.65$.
Table 4 Distribution of claspin expression by HR-HPV infection and cytological categories in 19 cervico-vaginal samples

\begin{tabular}{lcccc}
\hline $\begin{array}{l}\text { Claspin } \\
\text { expressionn (\%) }\end{array}$ & $\begin{array}{c}\text { HR-HPV } \\
\mathbf{n}(\%)\end{array}$ & $\begin{array}{c}\text { NILM } \\
\mathbf{n = 3}\end{array}$ & $\begin{array}{c}\text { L-SIL } \\
\mathbf{n = 7}\end{array}$ & $\begin{array}{c}\text { H-SIL } \\
\mathbf{n = 9}\end{array}$ \\
\hline Negative 5 (26.3) & Negative 3 (60.0) & 2 & 1 & $\backslash$ \\
& Positive 2 (40.0) & $\backslash$ & 2 & $\backslash$ \\
Positive14 (73.7) & Negative 0 (0.0) & $\backslash$ & $\backslash$ & $\backslash$ \\
& Positive 14 (100) & 1 & 4 & 9 \\
\hline
\end{tabular}

HR-HPV, High Risk Human Papillomavirus; NILM, Negative for Intraepithelial Lesion or Malignancy; L-SIL, Low Grade Squamous Intraepithelial Lesion; H-SIL, High Grade Squamous Intraepithelial Lesion.

uterine cervix as a consequence of the infection by HRHPV [11]. Although p16 is one of the most promising biomarker, and is being investigated in clinical settings [18], the immunohistochemical evaluation of p16 usually presents a limited reproducibility due to the lack of standardized criteria for the interpretation of immunostaining [19].

To our knowledge, this is the first study in which claspin expression has been analyzed in histological as well as cytological cervical specimens with the aim to establish whether this marker is related to the severity of cervical lesions and to HR-HPV infection. This approach represents the first step of the framework proposed by Arbyn to assess the potential use of a biomarker as a screening tool for cervical cancer [20].

When we firstly evaluated claspin level in a series of different cell lines, we evidenced an up-regulation of the protein only in the cervical cancer cell lines $\mathrm{SiHa}$, CaSki and HeLa. Afterwards, in human cervical tissues, we observed a significant positive correlation between the number of claspin immunoreactive nuclei/HPF and the severity of the lesion. In particular, while the minimum number of claspin-positive nuclei/HPF was almost the same in all the histological categories, the maximum value significantly increased from normal cervix to carcinomas. This latter value could be particularly useful in clinical practice contributing to define the risk of progression of each lesion. In fact, despite a marked overlap between the different entities, claspin high expression may identify those CIN1 prone to progression. On the other hand, high grade lesions displaying low expression may be prone to regression. However, only a prospective study may clarify the prognostic role of claspin. In a follow up study, a parallel analysis of p16 and claspin expression may be of interest, since p16 has been proposed as a prognostic biomarker. Our findings are mostly in agreement with recent data [7] showing that claspin levels are higher in human colon, lung, bladder and breast carcinomas than in the corresponding autologous normal tissues, even though we did not analyze autologous normal tissues. 
In the present study, we took our analysis one step further investigating whether claspin expression was differently modulated in the dysplastic lesions that precede the cancer. This methodological approach, together with the claspin reactivity score applied in this study, may provide more useful biological information to be translated into clinical practice.

Concerning the correlation between claspin and HRHPV infection, in our series of samples we found a statistically significant association between the protein expression and HR-HPV infection detected by the $\mathrm{HC} 2$ test, independently of the HR-HPV genotypes. This association might have a particular clinical value, since the $13 \mathrm{HR}-\mathrm{HPV}$ types detected by the HC2 test are responsible for the majority of the high grade lesions as well as cervical carcinomas (97\% and 93.6\% respectively) [21,22]. Therefore, we can hypothesize that claspin identifies almost all the high grade lesions and cancers. Interestingly, our study seems to evidence a correlation between claspin positivity and the presence of a CIN2+ lesion among the HR-HPV positive cases. There are no studies regarding the interaction between claspin expression and HPV infection in vivo, and only one in vitro study has been published so far [8]. The authors provide evidence that both HPVpositive and negative cervical cancer cell lines show increased baseline levels of claspin. Yet, HPV16positive cell lines show an accelerated proteolitic turnover which is probably due to HPV E7 oncoprotein. Therefore, the authors suggest that HPV16-infected cells can also enter mitosis in the presence of unrepaired DNA, probably overcoming the DNA damage checkpoint control. In this case, the accumulation of claspin attempts to restore cell cycle control reinforcing the G2-M checkpoint. These findings appear to be consistent with our results, and open the need to delve deeper into the matter by carrying out a more accurate investigation of the correlation between claspin and HR-HPV infection.

Focusing on cervical cytology, we found that claspin positivity was associated with HR-HPV positivity and consistently increased with the severity of cellular abnormalities. Immunoreactivity was mainly found among cases with a histologically confirmed diagnosis. These findings, although preliminary, may have relevant clinical implications, mainly in the management of HPV positive cases. In fact, the immunocytochemical detection of this biomarker may represent a novel and useful tool which is capable of identifying those HR-HPV infections associated to a lesion. In fact, HR-HPV testing, despite its high sensitivity, is limited by a low specificity in detecting high grade lesions, since the majority of HPV infections are transient and not linked to histologically confirmed cervical dysplasia [23].

\section{Conclusions}

Our findings indicate that in vivo claspin expression is significantly related to HR-HPV infection and lesion grade both in histological and cytological samples. Therefore, the analysis of claspin expression could be clinically relevant in the diagnosis of HPV-related cervical lesions, in particular when applied to cervicovaginal cytology. Moreover, giving information on the proliferation rate of each lesion, claspin immunostaining may contribute to the evaluation of progression risk, thus being helpful in patient management. Nevertheless, only large prospective studies may clarify the true clinical usefulness of claspin expression in distinguishing lesions with different progression potential.

\section{Abbreviations}

HR-HPV: High risk human papillomavirus; WNL: Within normal limits; CIN: Cervical intraepithelial neoplasia; SCC: invasive squamous cell carcinomas; NILM: Negative for intraepithelial lesion or malignancy; L-SIL: Low-grade intraepithelial lesions; H-SIL: High-grade intraepithelial lesions: IHC: Immunohistochemistry; HPF: High power field; HC2: Hybrid capture 2.

\section{Competing interests}

The Authors declare that they have no competing interests.

\section{Acknowledgements}

This study was supported by the Italian Ministry of Health and by the Associazione Italiana per la Ricerca sul Cancro (AIRC). Professor Thanos D. Halazonetis and Dr. Federico De Marco are gratefully acknowledged for generously providing the anti-claspin monoclonal antibody and the cell lines, respectively. We also would like to thank Michael Kenyon for his formal revision of the manuscript and Maria Assunta Fonsi for her secretarial assistance.

\section{Author details}

'Pathology Department, Regina Elena Cancer Institute, Via Elio Chianesi 53, 00144, Rome, Italy. ${ }^{2}$ Istituto di Ricerca Genetica e Biomedica, Consiglio Nazionale delle Ricerche, Pisa, Italy. ${ }^{3}$ Istituto Toscano Tumori, Florence, Italy. ${ }^{4}$ Sexually Transmitted Infections (STI) Unit, San Gallicano Dermatological Institute, Rome, Italy. ${ }^{5}$ Epidemiology Department, Regina Elena Cancer Institute, Rome, Italy. ${ }^{6}$ Oncologic Gynaecology Department, Regina Elena Cancer Institute, Rome, Italy.

\section{Authors' contributions}

$M B$ conceived of the study, wrote the manuscript and performed literature search and review; AM performed Western blotting analyses and revised the manuscript; AV and MGD evaluated the cytological and molecular findings and addressed relationships between molecular and pathological findings; FR performed immunohistochemical analysis and HPV testing; IT performed the statistical analyses; MC and EP performed histological analyses; GV helped in the enrollment of cases; MM participated in study design, supervised all the activities, and helped write the manuscript. All authors read and approved the final manuscript.

Received: 27 March 2012 Accepted: 25 June 2012 Published: 25 June 2012

\section{References}

1. Chini CC, Chen J: Claspin, a regulator of Chk1 in DNA replication stress pathway. DNA Repair 2004, 3:1033-1037.

2. Freire R, van Vugt M, Mamely I, Medema RH: Claspin. Timing the cell cycle arrest when the genome is damaged. Cell Cycle 2006, 5:2831-2834.

3. Tanaka K: Multiple functions of the S-phase Checkpoint mediator. Biosci. Biotechnol. Biochem 2010, 74:2367-2373

4. Chini CC, Chen J: Human claspin is required for replication checkpoint control. J Biol Chem 2003, 278:30057-30062. 
5. Focarelli ML, Soza S, Mannini L, Paulis M, Montecucco A, Musio A: Claspin inhibition leads to fragile site expression. Genes Chrom Cancer 2009, 48:1083-1090

6. Korzeniewski N, Spardy N, Duensing A, Duensing S: Genomic instability and cancer: lessons learned from human papillomaviruses. Cancer Lett 2011, 305:113-122.

7. Tsimaratou K, Kletsas D, Kastrinakis NG, Tsantoulis PK, Evangelou K, Sideridou M, Liontos M, Poulias I, Venere M, Salmas M, Kittas C, Halazonetis TD, Gorgoulis VG: Evaluation of claspin as a proliferation marker in human cancer and normal tissues. J Pathol 2007, 211:331-339.

8. Spardy N, Covella K, Cha E, Hoskins EE, Wells SI, Duensing A, Duensing S: Human papillomavirus 16 E7 oncoprotein attenuates DNA damage checkpoint control by increasing the proteolytic turnover of claspin. Cancer Res 2009, 69:7022-7029.

9. Benevolo M, Vocaturo A, Caraceni D, French D, Rosini S, Zappacosta R, Terrenato I, Ciccocioppo L, Frega A, Giorgi Rossi P: Sensitivity, Specificity, and Clinical Value of Human Papillomavirus (HPV) E6/E7 mRNA Assay as a Triage Test for Cervical Cytology and HPV DNA Test. J Clin Microbiol 2011, 49:2643-2650

10. Schweizer J, Lu PS, Mahoney CW, Berard-Bergery M, Ho M, Ramasamy $V$, Silver JE, Bisht A, Labiad Y, Peck RB, Lim J, Jeronimo J, Howard R, Gravitt PE, Castle PE: Feasibility study of a human papillomavirus E6 oncoprotein test for diagnosis of cervical precancer and cancer. J Clin Microbio/ 2010, 48:4646-4648.

11. Benevolo M, Mottolese M, Marandino F, Vocaturo G, Sindico R, Piperno G, Mariani L, Sperduti I, Canalini P, Perrone Donnorso R, Vocaturo A: Immunohistochemical expression of $\mathrm{p} 16^{\mathrm{INK} 4 \mathrm{a}}$ is predictive of HR-HPV infection in cervical low-grade lesions. Mod Pathol. 2006, 19:384-391.

12. Keating JT, Cviko A, Riethdorf S, Riethdorf L, Quade BJ, Sun D, Duensing S, Sheets EE, Munger K, Crum CP: Ki-67, Cyclin E, and p16 $6^{\text {INK4a }}$ are complimentary surrogate biomarkers for human papilloma virus-related cervical neoplasia. Am J Surg Pathol 2001, 25:884-891.

13. Khan $A M$, Singer $A$ : Biomarkers in cervical precancer management: the new frontiers. Future Oncol 2008, 4:515-524.

14. De Marco F, Perluigi M, Foppoli C, Cini C, Giorgi A, Grillo C, De Marco F, Butterfield DA, Schininà ME, Coccia R: UVB irradiation down-regulates HPV-16 RNA expression: implications for malignant progression of transformed cells. Virus Res 2007, 130:249-259.

15. Yerushalmi R, Woods R, Ravdin PM, Hayes MM, Gelmon KA: Ki67 in breast cancer: prognostic and predictive potential. Lancet Oncol 2010, 11:174-183.

16. Solomon D, Davey D, Kurman R, Moriarty A, O'Connor D, Prey M, Raab S, Sherman M, Wilbur D, Wright T Jr, Young N, for the Forum Group Members and the Bethesda 2001 Workshop: The Bethesda system: terminology for reporting results of cervical cytology. JAMA 2001, 2002(287):2114-2119.

17. Badr RE, Walts AE, Chung F, Bose S: BD ProEx C: a sensitive and specific marker of HPV-associated squamous lesions of the cervix. Am J Surg Pathol 2008, 32:899-906.

18. Carozzi F, Confortini M, Dalla Palma P, Del Mistro A, Gillio-Tos A, De Marco L, Giorgi-Rossi P, Pontenani G, Rosso S, Sani C, Sintoni C, Segnan N, Zorzi M, Cuzick J, Rizzolo R, Ronco G, New Technologies for Cervical Cancer Screening (NTCC) Working Group: Use of p16-INK4A overexpression to increase the specificity of human papillomavirus testing: a nested substudy of the NTCC randomised controlled trial. Lancet Oncol 2008, 9:937-945.

19. Tsoumpou I, Arbyn M, Kyrgiou M, Wentzensen N, Koliopoulos G, MartinHirsch P, Malamou-Mitsi V, Paraskevaidis E: p16 ${ }^{\text {INK4a }}$ immunostaining in cytological and histological specimens from the uterine cervix: a systematic review and meta-analysis. Cancer Treat Rev 2009, 35:210-220.

20. Arbyn M, Ronco G, Cuzick J, Wentzensen N, Castle PE: How to evaluate emerging technologies in cervical cancer screening? Int J Cancer 2009, 125:2489-2496

21. Bosch FX, Burchell AN, Schiffman M, Giuliano AR, de Sanjose S, Bruni L, Tortolero-Luna G, Kjaer SK, Muñoz N: Epidemiology and natural history of human papillomavirus infections and type-specific implications in cervical neoplasia. Vaccine 2008, 26(Suppl 10):K1-16.

22. Li N, Franceschi S, Howell-Jones R, Snijders PJ, Clifford GM: Human Papillomavirus type distribution in 30,848 invasive cervical cancers worldwide: Variation by geographical region, histological type and year of publication. Int J Cancer 2011, 128:927-935
23. Cuzick J, Arbyn M, Sankaranarayanan R, Tsu V, Ronco G, Mayrand MH, Dillner J, Meijer CJ: Overview of human papillomavirus-based and other novel options for cervical cancer screening in developed and developing countries. Vaccine 2008, 26(Suppl 10):K29-41.

doi:10.1186/1479-5876-10-132

Cite this article as: Benevolo et al:: Claspin as a biomarker of human papillomavirus-related high grade lesions of uterine cervix. Journal of Translational Medicine 2012 10:132.

\section{Submit your next manuscript to BioMed Central and take full advantage of:}

- Convenient online submission

- Thorough peer review

- No space constraints or color figure charges

- Immediate publication on acceptance

- Inclusion in PubMed, CAS, Scopus and Google Scholar

- Research which is freely available for redistribution 